\title{
Al Qaeda at the bar: coordinating ideologues and mercenaries in terrorist organizations
}

\author{
Kjell Hausken ${ }^{\mathrm{a}}$, Sheheryar Banuri ${ }^{\mathrm{b}}$, Dipak K. Gupta ${ }^{\mathrm{c}}$, and Klaus Abbink ${ }^{\mathrm{d}}$ \\ ${ }^{a}$ Faculty of Social Sciences, University of Stavanger \\ 4036 Stavanger, Norway \\ ${ }^{\mathrm{b}}$ School of Economics, University of East Anglia \\ Norwich, NR4 7TJ, United Kingdom \\ ${ }^{c}$ Department of Political Science, San Diego State University \\ San Diego, CA 92129, USA \\ ${ }^{\mathrm{d}}$ Department of Economics, Monash University \\ Melbourne, Victoria 3800, Australia
}

April 20, 2015

Corresponding Author: Kjell Hausken; kjell.hausken@uis.no; Faculty of Social Sciences, University of Stavanger, 4036 Stavanger, Norway; Tel.: +47 51 831632; Fax: +47 51831550

\begin{abstract}
Most terrorist groups have limited lifespans. A number of scholars and casual observers have noted that terrorist organizations often are comprised of two types of participants: ideologues or "true believers" dedicated to the group's cause, and mercenaries, who are adept at raising money through illegal means. The latter are interested primarily in their personal gains and have relatively little ideological commitment. Terrorist groups need both participants in order to function effectively. The purpose of the study is to understand the impact of communication on the compositions of terrorist groups. Three experimental treatments consider a coordination problem, and focus on the behavior of the mercenaries. Participants choose whether or not to participate in a terrorist attack. Payoffs are U-shaped in the number of participants, and increase with the number of successful attacks. The treatments allow communication between a leader and frontline fighters ("leader" treatment) or among the frontline fighters themselves ("communication" treatment). In the first treatment, a group leader can post messages to the members, which has a $19 \%$ coordination success rate. For the communication treatment, all participants can post messages anonymously to each other, which yields a $27 \%$ coordination success rate. By contrast, the baseline ("no communication" treatment) shows a success rate of $11 \%$. We conclude from our experimental evidence that disrupting communications among the frontline fighters is more effective in terminating terrorist organizations.
\end{abstract}

Keywords: Terrorism, terrorist organizations, ideologues, mercenaries, laboratory experiment, coordination

JEL Classification Codes: C72, C91, C92, D71, H41 
1 Introduction

Most terrorist groups have limited lifespans. Similar to small businesses, most fizzle out within the first few years (Crenshaw 1991; Rapoport 1992; Gaibulloev and Sandler 2013). Gaibulloev and Sandler (2014) find three possible endings for terrorist groups: (1) splintering from internal factors, (2) being defeated by force, and (3) joining the political process / achieving victory. One common outcome of splintering, however, is transformation into a criminal group (Gupta, 2008). ${ }^{1}$

Shapiro (2013) outlines two basic tradeoffs confronting terrorist groups that potentially speed up their demise: the security-control tradeoff ${ }^{2}$ and the security-efficiency tradeoff. ${ }^{3}$ In fact, terrorist groups are rife with moral hazard problems and face discipline and management challenges (Shapiro and Siegel 2012; Faria and Arce 2012). Furthermore, terrorist groups are unique in that communication within the group is hindered owing to security concerns. One clear goal of counterterrorism policy, therefore, is to disrupt communication within terrorist groups.

In this paper, we use a laboratory experiment to study the impact of communication on the demise of terrorist groups. Following Shapiro's (2013) tradeoffs, we examine the effectiveness of two counterterrorism policies designed to interrupt communication in terrorist groups: (1) severing communication between a terrorist leader and frontline fighters (security-control tradeoff), and (2) severing communication between frontline fighters

\footnotetext{
${ }^{1}$ For instance, Colombia's FARC was created as a Marxist revolutionary group, yet transformed into a drug trafficking cartel (Betancourt 2011). Several splinter groups of the IRA in Northern Ireland (the longest surviving terrorist organization) turned to criminal activities (English 2004). In addition, subgroups of the same movement can vary in their ideological commitments to a cause: the Maoist insurgents in India's Andhra Pradesh state are highly ideologically motivated, while in the more lawless state of Bihar, terrorist groups are much more criminal in their orientation (Mukherjee and Yadav 1980; Singh 2006).

${ }^{2}$ In order to maintain secrecy, the ideologically motivated leaders must rely on the lower-level operatives, whose goals often diverge, to carry out tasks with minimal supervision, yielding a principal-agent problem. (Shapiro 2013, p. 250). Shapiro and Siegel (2007) similarly find that leaders delegate financial and logistical tasks to middlemen, but cannot monitor them perfectly for security reasons.

${ }^{3}$ Terrorist groups become inefficient because communication between members must be minimized to maintain secrecy.
} 
themselves (security-efficiency tradeoff). We devise a game based on the "bar problem" (Arthur 1994), which captures the coordination difficulties faced by terrorist groups in planning terrorist attacks. Next, we test the impact of these policies on the ability of the terrorist group to coordinate successful attacks. ${ }^{4}$ We find that disrupting communication between frontline fighters is more effective (in bringing about the demise of terrorist groups) than disrupting communication between the leader and the frontline fighters.

While various aspects of the lifecycles of terrorist groups are well known (Gupta et al. 2009; Phillips 2011; Blomberg et al. 2011) and are important for formulating proper counterterrorism policies, few attempts have been made to understand the internal compositions of terrorist groups. Based on a theoretical model of human behavior, Gupta $(1990,2008)$ identifies three types of agents operating within terrorist groups, which are distinguished by their respective motivations for joining the group. First, the "ideologues" are agents having strong commitments to the terrorist groups' political objectives and are willing to sacrifice their own individual interests for the greater good of the community. ${ }^{5}$ Second, the "mercenaries" are agents with weak (if any) commitment to the group's ideology. Their primary function is to procure funds for the group's operation through sundry illegal activities. Third, the "captive participants" are agents that are coerced into serving the groups' interest, but do not have ideological commitments to the group, nor do they derive financial benefits from membership. ${ }^{6}$

Since captive participants do not join voluntarily and receive no benefits, in this article we will concentrate on the ideologues and the mercenaries. It is imperative that

\footnotetext{
${ }^{4}$ The experimental design uses a free-form communication technology as opposed to sending specific messages (which is a strategy used to control the content of communication). In a complex game such as the one we model, it is necessary to allow free form communication so as to capture the full range of strategies employed by the participants. We analyze the content of the messages in section 5.

${ }^{5}$ Gupta $(1990,2008)$ argues that in analyzing collective action, individuals are motivated by concerns for the welfare of the group in addition to their own self-interest. This motivation, also known as "other regarding" preferences in behavioral economics (Bowles and Gintis 2011), is critical for understanding terrorist groups.

${ }^{6}$ The captive participants continue to be a part of the terrorist group because their costs from defection outweigh the benefits.
} 
terrorist organizations strive to achieve an optimal mix of the two types of participants.

While mercenaries are necessary for carrying out terrorist operations, ${ }^{7}$ in large numbers they alter the orientation of the group by driving away the ideologues, converting them into criminals, or both. ${ }^{8}$ In the process, an ideological group transforms into, in effect, a criminal organization. The difference between the two types of groups' actions rests on their respective motivations. ${ }^{9}$ The most common motivations of terrorist groups are to change the political order of a society and to fight for certain social issues or causes, the benefits of which do not remain confined to the members of the group (public goods). By contrast, the primary motivations of criminal groups are to obtain money and power for their members (private or club goods). ${ }^{10}$

Gupta (2008) argues that, over time, some terrorist groups transform themselves into criminal groups. In fact, all of the world's known terrorist groups can be placed on a continuum running from purely ideological to purely criminal. ${ }^{11}$ Based on published memoires and internal communications, Shapiro and Siegel $(2007,2012)$ demonstrate the difficulties of maintaining ideological cohesion as the group recruits more members with

\footnotetext{
${ }^{7}$ Of course, terrorist groups can vary widely in their structures and their need for mercenaries in order to raise funds. The START database (http://www.start.umd.edu/start/gtd/) classifies terrorist groups both with and without benefactors. From this, we have identified the following 13 groups that are relevant for the type of terrorist group discussed in our model and experiment. These groups do not have a benefactor and recruit criminal mercenaries to finance their operations: examples include Abu Sayyaf Group, All Tripura Tiger Force, Armed Islamic Group, Communist Party of India (Maoist), Continuity Irish Republican Army, Basque (Euskadi ta Askatasuna), Loyalist Volunteer Force, National Democratic Front of Bodoland, People's Revolutionary Party of Kangleipak, Ulster Defense Association, Ulster Volunteer Force, Revolutionary Armed Forces of Colombia (FARC) and Shining Path (Carter 2012).

${ }^{8}$ Such conversion has been observed in terrorist groups such as the FARC (Cronin 2006) and the Abu Sayyaf (Rogers 2003).

${ }^{9}$ Cronin (2009, p. 148) points out that, "[c]riminal groups and terrorist groups often engage in similar behavior, including kidnappings, assassinations, and bombings, but their purposes are different."

${ }^{10}$ Similarly, Hoffman (1998, p. 43) points out that, "the terrorist is fundamentally an altruist: he believes he is serving a 'good' cause designed to achieve a greater good for a wider constituency ... The criminal, by comparison, serves no cause at all, just his own personal aggrandizement and material satiation."

${ }^{11}$ The internal compositions of terrorist groups depend on many factors. Most begin as ideological groups; some are able to maintain their ideological orientations and sustain themselves over many years (such as the IRA, Hamas, or Hezbollah); some transform into criminal organizations, such as FARC or Abu Sayaaf (Cronin 2006); some, such as the Maoists in India, fracture along ideological lines (Gupta 2008, p. 175; Singh 2006), and most, such as the Japanese Red Army or the Baader Meinhof "gang", eventually die out. Which path a terrorist group takes depends on its composition of the three types of actors (Dishman 2006; Gupta 1990, 2008).
} 
questionable commitments to the group's ideology. ${ }^{12}$ Shapiro and Siegel (2012, p. 405) observe: "Substantial evidence indicates that members of terrorist groups are not uniformly motivated by the cause, are not equally willing to sacrifice for the cause..."

This suggests that the motivations of the group determine whether it is a criminal or a terrorist group, and that this depends on the mix of agents that comprise the group. This mix of agents is influenced by the activities undertaken by the group. Terrorist groups with multiple successful attacks attract ideologues into its fold, thereby increasing the proportion of ideologues and reinforcing its ideological mindset. Alternatively, terrorist groups whose attacks are unsuccessful drive ideologues away, owing to their ineffectiveness in bringing about change, and thus are more likely to become criminal groups. ${ }^{13}$

This paper focuses on the role of mercenaries in terrorist groups, which can be attracted or repelled either by financial incentives or by coercion (change in the cost of compliance). Ideologues are more difficult to coerce, but do respond to the effectiveness of the terrorist group in carrying out attacks. In the face of repeated failures by the terrorist group, ideologues abandon the cause, leaving behind a greater proportion of mercenaries; consequently, the group transforms into a criminal organization (see, e.g., Holland and McDonald 1984; Heskin 1985; Palmer 1995). We develop a model of the internal composition of a terrorist group, and assume that terrorist groups are comprised of two types

\footnotetext{
${ }^{12}$ In reality, the activities of criminal groups and terrorist groups overlap considerably, making them hard to distinguish based on observed behavior alone. For example, the drug cartels in Mexico (criminal groups) and $\mathrm{Al}$ Qaeda in Afghanistan (a terrorist group) both engage in beheadings of their enemies. The Naxalites in India kidnap, Northern Ireland's IRA robbed banks, Peru's Shining Path was deeply involved in drug trafficking, and many terrorist groups engage in money laundering. Similarly, criminal groups engage in violent acts to terrorize organized society so that they can pursue their moneymaking operations without interference.

${ }^{13}$ The group becomes a criminal organization because fund-raising activities by the group (which necessarily are extra-legal) continue to pay for planning and logistics; however, the payoff from a successful attack never arrives, causing ideologues to abandon the cause, leaving mercenaries behind to continue the extra-legal fundraising activities.
} 
of participants: ${ }^{14}$ ideologues and mercenaries. ${ }^{15}$ The two types of participants are assumed to be rational decision makers. ${ }^{16}$

We posit that in order to be successful, terrorist attacks require an optimal number of mercenaries. Expanding the group is in the interest of the mercenaries since they will have greater profit-making opportunities in the future, but in order to grow the group, they must forgo immediate profits for the good of the group. Thus, mercenaries confront a coordination problem and a social dilemma (Olson 1965; Tullock 1974), such that they can share in immediate profits, but face reductions in future earnings for themselves, and for the group as a whole. This is an important issue that has not been addressed in the literature.

The game models terrorist attacks as a coordination problem, wherein the optimal number of mercenaries must participate in the attack for it to be successful. The optimal number of mercenaries depends on the number of ideologues presently belonging to the group (as detailed in the next section). ${ }^{17}$ Mercenaries have an incentive to participate in the attacks if this generates revenue for them exceeding their outside option.

Communication among agents is a necessary ingredient for successful terrorist attacks. Counterterrorism policies aimed at disrupting communications can reduce the incidence and consequently, the effectiveness of terrorist attacks, resulting in ideologues leaving the group, and hastening the terrorist groups' transformation into a criminal group.

We analyze two types of policies designed to interrupt communication within terrorist groups. ${ }^{18}$ The first policy focuses on severing communications between a terrorist leader (an

\footnotetext{
${ }^{14}$ The third type, "captive participants", is not considered in the experiments described below.

${ }^{15}$ In reality few human beings are pure altruists or pure self-utility maximizers. That is, most individuals have mixed motives (Andreoni 1989, 1990; Rose-Ackerman 1996; Hausken 1996). However, we impose strict behavioral assumptions for the sake of tractable analysis.

${ }^{16}$ See Sandler (2014) for a recent review of five areas of terrorism research that assume them to be rational actors.

${ }^{17}$ One critical assumption is that the ratio of mercenaries to ideologues is stable, whereas in practice it may fluctuate. The stability condition is used for simplicity, as the game is already rather complex.

${ }^{18}$ Communications can be disrupted by arresting operatives, monitoring and preventing face-to-face meetings, blocking or intercepting electronic (such as by phone, social media and email) and written messages, and letting members know that they are being watched closely.
} 
ideologue) and frontline actors (mercenaries and ideologues). The second policy focuses on severing communications between the frontline actors themselves. Disrupting communications makes it more difficult to coordinate terrorist activities, leading to more failed attacks, thereby prompting ideologues to abandon the cause. We show that severing frontline communications is more effective in terminating terrorist organizations than disrupting communications between the leader and frontline agents.

The scale of a terrorist attack is a function of the number of ideologues in the group. Attacks on larger scales increase the number of ideologues in the group. ${ }^{19}$ Successful attacks draw additional ideologues, while unsuccessful attacks drive ideologues away (Phillips 2011; Crenshaw 1991; Gaibulloev and Sandler 2013). Any terrorist organization that can launch a large-scale attack against its enemies is likely to garner substantial media attention, as well as signal ideological commitment to its political base. For instance, Ahmed (2005) argues that the popularity of Hamas among the Palestinians rests on its ability to stage suicide attacks deep inside Israel as well as its demonstrated devotion to its stated ideology. Abu-Amr (1993) delineates the historical and political background of Hamas and provides more detailed reasons for the support and credibility it enjoys..$^{20}$ Besides attracting a larger number of ideologues, the enhanced reputation and the associated increase in power (as a result of

\footnotetext{
19 The extant literature acknowledges the fact that terrorist attacks vary in their scale. The 9/11 attacks were qualitatively different from kidnapping of ordinary US citizens by a terrorist organization in a conflict zone. We argue that the scale of an attack reflects a group's relative ideological strengths. Ideologues aim to mix violence with theater for maximum political impact, while mercenaries prefer to work under the radar. A group's choice of target speaks volumes about its commitment to the cause and contributes to terrorisms' symbolic value (Berman and Laitin 2005; Atran 2002; Pape 2003). The choice of hard targets, which may include military bases and targets of national significance, would surely please the group's political base (Bloom 2005) and confer a strategic advantage in acquiring a larger "market share" of that base (Gupta and Mundra 2005). Schmid and de Graaf (1982) argued that, in the final analysis, terrorism is a form of political communication. ${ }^{20}$ Hamas is an offshoot of the Muslim Brotherhood in Egypt, with an extensive history in the occupied territories. It is a strictly Sunni group. It developed an uneasy alliance with the Shiite, Iranian-supported group Hezbollah, but it relies mostly on contributions from the larger Palestinian community and from Sunni Arab countries in the Middle East. After Hamas formed a government in the Gaza strip in 2006, it has been able to raise money through taxes, fees, and fines similar to all other governments. It has also benefited from cross-border smuggling between Israel and Egypt (Mishal and Sela 2000; also see US State Department: http://www.state.gov/j/ct/rls/crt/2013/224829.htm).
} 
successful attacks) also attract a large number of opportunistic mercenaries. ${ }^{21}$ The

proliferation of Al Qaeda-affiliated groups after 9/11 provides ample evidence of the importance of large-scale operations. $^{22}$

Although scholarship on the subject of terrorism has skyrocketed in recent years, we know of no experimental study that aims at understanding how communication contributes to the decline of terrorist organizations. Hence, this study attempts to capture the endogenous forces that determine the internal compositions of terrorist organizations. We develop a game theoretic paradigm that captures the essential features of terrorist groups. This is of particular interest to policy makers because we can test various policy instruments within this environment aimed at reducing the sustainability of terrorist groups. Section 2 presents the model and experimental design. Section 3 solves the game. Section 4 provides implementation details. Section 4 and 5 present the results. Section 6 discusses the overall implications of our findings. In section 7 we conclude by pointing out some possible areas of future research.

\section{Model and experimental design}

\subsection{The mercenaries' payoff function}

\footnotetext{
${ }^{21}$ Of course, the popularity enjoyed by Hamas is explained not just by suicide attacks. As Mannes et al. (2008) demonstrate (using a Stochastic Opponents Modeling Agents framework), a large component of Hamas's popularity is attributable to the social services it provides, through which the group is able to recruit further suicide bombers. In addition, strategic alliances with other terrorist groups likewise allow Hamas to expand its operations because cooperation facilitates access to additional training, funding, and equipment (Mannes et al. 2008). In order to raise their profiles, terrorist groups need to carry out attacks on ever-larger scales to continue to attract both ideologues and mercenaries to the cause.

${ }^{22}$ Although it is assumed that a large-scale attack would increase the visibility, reputation, and power of an insurgent group, it could also draw harsh counterattacks from opposition groups. Furthermore, even successful attacks can backfire. For instance, in the 1990s the IRA began what they called "proxy bombing," whereby it would compel innocent victims to drive explosive-laden vehicles through British checkpoints and then blow them up using remote control devices. These acts were seen as evil by Northern Ireland's Catholics and caused the IRA to lose significant public support (Maloney 2002).
} 
We model the decisions of mercenary agents of terrorist groups to participate in a terrorist attack as a variant of the "Bar problem" posited by Arthur (1994). ${ }^{23}$ In this problem, individuals independently and simultaneously choose whether or not to go to a popular bar. This action incurs a cost of travel, but accrues benefits from participation. However, since the bar has a capacity constraint, only a subset of the individuals enjoys benefits.

We consider a game with $\mathrm{M}=10$ mercenary participants over $\mathrm{T}=10$ periods. In each period every mercenary has one strategic choice variable: to participate or not in a terrorist attack (i.e., go to the bar). We assume that each terrorist attack requires an optimal number of participating mercenaries for it to be successful: too few mercenaries render the attack unsuccessful owing to a lack of resources; too many mercenaries increase the chance of detection by counterterrorist groups. ${ }^{24}$

Unsuccessful attacks lead to a reduction in the number of ideologues in the terrorist group in subsequent periods (through capture or disillusionment). Successful attacks attract new ideologues to the terrorist group (through greater outreach and exposure). ${ }^{25}$

The mercenaries' payoffs from participation in terrorist attacks depend crucially on two factors, the number of ideologues currently in the terrorist group $\left(\mathrm{N}_{\mathrm{i}}\right)$, and the number of mercenaries participating in the attack $\left(\mathrm{N}_{\mathrm{m}}\right)$. This yields a payoff function for each mercenary as:

\footnotetext{
${ }^{23}$ Our experiment focuses on the decisions of mercenaries, as they are motivated by economic incentives. The incentives of ideologues (by contrast) largely are ideological and difficult to combat as a matter of policy. That is, policies targeting ideologues engage in undermining terrorist ideology, which is outside the scope of this paper.

${ }^{24}$ Arthur (1994) assumes that each individual choosing to go once the bar has reached full capacity incurs the cost of travel but does not enjoy any benefits. We assume that all $\mathrm{M}=10$ participants wanting to visit the bar, i.e., participate in the terrorist attack, can do so and reap the benefits. However, if the attack includes any number of participants other than the optimal number, the attack is deemed unsuccessful, which has payoff implications in subsequent periods.

${ }^{25}$ History is quite clear on how success in carrying out spectacular attacks attract attention of like-minded ideologues from all over the world. The global spread of the Al Qaeda brand is closely tied to its successful attacks starting with the attack on the US embassies in East Africa in 1998, the USS Cole in Yemen in 2000, and finally, the 9/11 attacks (Rivers 2014; Wright 2007).
} 
$\pi_{m}=\left\{\begin{array}{l}d_{1}\left(\frac{N_{i}}{N_{m}}\right)+d_{2} N_{m} \text { if he participates in the attack, i. e. , } 1 \leq N_{m} \leq M \\ D \text { if he does not participate in the attack, i. e. , } N_{m}=0\end{array}\right.$

where $d_{1}$ and $d_{2}$ are parameters and D is a fixed outside option for the mercenary. We assume that the ratio $d_{1} / d_{2}$ exceeds 1 , which quantifies the importance of ideologues for the mercenary's payoff. Mercenaries have an incentive to participate in the attack (as long as $\left.\left[d_{1}\left(\frac{N_{i}}{N_{m}}\right)+d_{2} N_{m}\right]>D\right)$, and to encourage other mercenaries to participate. ${ }^{26}$

Since the participation decisions of mercenaries are decentralized, the eventual group composition for any attack is endogenous. The first line in equation (1) is $\mathrm{U}$ shaped in $\mathrm{N}_{\mathrm{m}}$, with a first derivative of $\frac{\partial \pi_{m}}{\partial N_{m}}=\frac{-d_{1} N_{i}}{N_{m}^{2}}+d_{2}$, which can be positive or negative, and with a positive second derivative $\frac{\partial^{2} \pi_{m}}{\partial N_{m}^{2}}=\frac{2 d_{1} N_{i}}{N_{m}^{3}}>0$. The $N_{i} / N_{m}$ term means that it is extremely lucrative to be the first participating mercenary, imposing a high burden of responsibility on the lone mercenary, which is reflected in his payoff. It also captures the importance of ideologues to the mercenaries' payoffs, but that importance is reduced if additional mercenaries participate in the attack.

As $N_{m}$ increases, the payoff reaches a minimum $2 \sqrt{N_{i} d_{1} d_{2}}$ when $N_{m}=\sqrt{N_{i} d_{1} / d_{2}}$, and thereafter increases approximately linearly. Available mercenaries have an incentive to participate in the attack (as long as the expected payoff is greater than D), yielding an overpopulation of mercenaries, and increasing the probability of an unsuccessful attack.

Fig. 1 plots each mercenary's payoff, $\pi_{m}$, as a function of the number of mercenaries $\left(N_{m}\right)$ and the number of ideologues $\left(\mathrm{N}_{\mathrm{i}}\right)$, where $\mathrm{D}=1000, d_{1}=200, d_{2}=100, M=10$ (parameters

\footnotetext{
${ }^{26}$ Note that the mercenary's payoff is not conditional on the success of an attack, though successful attacks do indeed increase overall payoffs by attracting more ideologues in future periods. We assume that all benefits from participation (including psychic benefits derived from simply participating) are modeled in the payoff function $d_{1}\left(\frac{N_{i}}{N_{m}}\right)+d_{2} N_{m}$. If mercenaries captured additional payoffs conditional on the success of an attack, then the incentive to coordinate would be even more powerful for the mercenaries. This would encourage greater separation across the experimental treatments and make our results even stronger as the costs of mis-coordination would rise. Therefore, our results could be considered a conservative estimate.
} 
used in the experiment). First, each mercenary benefits from the presence of ideologues, and thus a larger $\mathrm{N}_{\mathrm{i}}$ provides a bigger payoff $\pi_{m}$ regardless of $N_{m}$. Second, when $\mathrm{N}_{\mathrm{i}}=0$ (i.e., a criminal group) the payoff $\pi_{m}$ increases linearly in $N_{m}$. Third, when $\mathrm{N}_{\mathrm{i}}>0$, the payoff $\pi_{m}$ is $\mathrm{U}$ shaped in $N_{m}$. When $N_{m}$ is small, the terrorist attack is motivated by ideology, so the choice of targets is based on political payoffs to the group, rather than economic payoffs. When $N_{m}$ is large, the terrorist attack is motivated by a combination of political and economic payoffs, yielding the $\mathrm{U}$ shape in the payoff function. ${ }^{27}$

\section{Insert Figure 1 about here}

The U-shaped payoff function is predicated upon the following assumptions:

1. We assume for simplicity that all mercenaries share the spoils equally. ${ }^{28}$

2. We assume that as the number of ideologues declines (relative to the number of mercenaries), so does the scale of attacks, and fewer targets are chosen. This is because, while ideologues are motivated politically (want to publicize their cause: "terrorism is part violence, part theater"), mercenaries are motivated economically (and want to operate under the radar). ${ }^{29}$

3. We assume that each additional mercenary's contribution to the mercenaries' total payoff is non-linear and, more specifically, $\mathrm{U}$ shaped in $\mathrm{N}_{\mathrm{m}}$. The first mercenary earns a high payoff owing to providing skills otherwise lacking. More mercenaries need to share similar payoffs. Beyond a certain ratio, the mercenaries influence the choice of target, and payoff increases convexly as $\mathrm{N}_{\mathrm{m}}$ increases.

\footnotetext{
${ }^{27}$ See Gupta $(1990,2008)$ for an expanded discussion of how mercenaries in terrorist groups earn the payoffs illustrated in Fig. 1.

${ }^{28}$ The shape of the payoff function will change if the payoffs for the mercenaries are unequal, such that the top leaders receive disproportionate shares of the spoils. In those circumstances, the crowding effects will be different based on an actor's position within the organizational hierarchy. Analyzing unequal payoffs means analyzing organizational structure, which is left for future research.

${ }^{29}$ This begs the question: what determines the "scale" of attack? We posit that a large-scale attack should include the choice of target, extent of media coverage, number of casualties and, ultimately, the approval of the terrorist group's political base.
} 
4. We assume that mercenaries and ideologues contribute differently to the mercenaries' payoff, expressed by $\mathrm{d}_{1}>\mathrm{d}_{2}$. The inequality indicates that an additional ideologue's contribution to the mercenary's payoff is more important than an additional mercenary's contribution.

5. We assume that the group is small, because at this point in the terrorist group's lifecycle it is most vulnerable and counterterrorism policies are more likely to be effective.

\subsection{The experimental design with three treatments}

Terrorist attacks have payoff consequences. Each successful attack attracts ideologues to the terrorist group. Unsuccessful attacks dissuade ideologues. Therefore, the payoff function for the mercenaries in subsequent periods increases/decreases based on success.

We start the game with a terrorist group containing 20 ideologues. A successful terrorist attack requires a fixed number of mercenaries to participate given the number of ideologues in the terrorist group. We assume that one mercenary is needed for every four ideologues. ${ }^{30}$

As mentioned, the experiment is played with $M=10$ participants in the role of mercenaries over $\mathrm{T}=10$ periods. Each participant (in each period) has to decide simultaneously whether or not to participate in the terrorist attack. The payoffs are provided to each participant, with potential earnings in the period determined by the number of other participants also choosing to participate, and their outside option (D). For an attack to be successful (using our parameters) in the first period, we require five mercenaries to participate in the attack (since the group has 20 ideologues). If exactly five mercenaries

\footnotetext{
${ }^{30}$ We keep this ideologue-mercenary ratio constant throughout the experiment. This ratio reflects the idea that larger terrorist groups engage in attacks on greater scales, requiring a larger number of mercenaries. Keeping this ratio constant simply means that smaller numbers of ideologues carry out smaller scale attacks, which require fewer mercenaries.
} 
participate in the attack, the group attracts two additional ideologues in the next period. If any other number of mercenaries (between zero and ten) participates, the group loses two ideologues. This means that the payoffs to the mercenaries change in subsequent periods based on the success (failure) of the attack in the current period.

Participants make their participation decisions simultaneously. They are fully informed in every period: they know how many participants participated in the attack in the previous period. In addition, each participant is told his/her earnings (for the current period, and overall earnings so far), the payoffs in the next period, and the target number of participants. The game lasts for ten periods. At the end of the tenth period, the game is restarted (as a surprise) and continues for an additional ten periods. This is to ensure complete understanding of the game and to control for the effect of learning. This restart comes as a surprise to ensure limited spill overs from the first ten periods. We use neutral terms (such as "participate in an attack") to prevent participants from being ideologically biased in their decision-making. ${ }^{31}$

We run three treatments: (1) baseline, (2) leader and (3) peer communication. The baseline proceeds as above. In the leader treatment, the game includes an additional participant, which we call the "leader". This participant is an ideologue, and his payoff increases with more ideologues in the group, but decreases in the absolute distance between ideologues and mercenaries. Formally:

$$
\pi_{i}=c_{1}\left(N_{i}-\left|N_{i}-g N_{m}\right|\right)
$$

where $c_{1}$ is an experimental parameter, and $g$ is the optimal ratio of ideologues to mercenaries. $\mathrm{N}_{\mathrm{i}}$ is set at 20 for the first period (as above). If the target number of mercenaries

\footnotetext{
31 An alternate method would be to adopt loaded terms, such as "terrorist attacks" and "terrorist groups". However, using such loaded terminology with university students is certainly not appropriate in capturing the core decision problem faced by mercenaries. That is to say, no mercenary belonging to a terrorist organization would be deterred by the use of the word "terrorist." However, it would be naïve to suggest that university students' decisions would remain unbiased were loaded instructions to be used.
} 
participating is met, the number of ideologues increases by two in the next period. If it is not met, the number decreases by two. Note that this means that by period 10 , if no successful terrorist attacks have taken place, all ideologues abandon the cause. As the number of ideologues in the group increases (decreases) by four, the target number of participants participating increases (decreases) by one. The leader is informed of these facts, and is provided with the optimal number of mercenaries needed for a successful attack. The leader's payoff is highest when the target number of mercenaries is met. Thus, the leader has clear incentives to organize a successful attack. The leader can post messages (i.e., communicate), which can be viewed by all of the mercenaries. However, the mercenaries are unable to communicate, either with the leader, or among themselves. In addition, each of the ten mercenaries is given an anonymous ID number (1 through 10) to help facilitate organization by the leader.

Our final treatment (peer communication) does not include a leader, but allows mercenaries to communicate with each other (i.e., post messages that everyone can read). Everything else remains identical to the baseline treatment. These two treatments implement communication in two different ways. When comparing either communication treatment with the baseline treatment, we can gauge the effect of policies attempting to disrupt communications either between the ideologues and the mercenaries (leader compared to baseline) or between the mercenaries themselves (peer communication compared with baseline).

Finally, as explained in the next subsection, the parameters and the basic model inform the payoff function given to subjects; they are unrelated to the treatment. The experiment simply manipulates communication pathways and leadership, but does not change the basic setup of the experimental design. While it is possible that the treatment may interact with the payoff function in complex, unforeseen ways, that possibility seems remote. 
In fact, from the communication transcripts it was clear that subjects worked towards achieving the target mix of mercenaries so as to expand the size of the group and capture larger payoffs in future periods.

To summarize, our experiment begins with a terrorist group of 20 (simulated) ideologues and ten available mercenaries. Using parameter values of $D=1000, d_{1}=200$, $d_{2}=100$, the ten participants decide simultaneously whether or not to participate in a terrorist attack in every period (for a total of 10 periods). Successful attacks cause the group to expand, while unsuccessful attacks shrink it. In each period, participants know their profits from participating under all scenarios, know their outside option, and the number of participants needed for an attack to succeed. They are asked to coordinate, even though they have few incentives to do so.

\section{Solving the game}

Finite games commonly are solved by backward induction, starting with the last period T. In this case, the game is quite complex, so we ignore mixed strategy equilibria. First, let us consider the stage game. A mercenary participates in the attack if

$$
d_{1}\left(\frac{N_{i}}{N_{m}}\right)+d_{2} N_{m}>D=>N_{i} \geq \frac{\left(D-d_{2} N_{m}\right) N_{m}}{d_{1}}
$$

which compares the payoff for participation in equation (1) with the payoff for no participation (D). The expression $\frac{\left(D-d_{2} N_{m}\right) N_{m}}{d_{1}}$ is inverse $\mathrm{U}$ shaped with a maximum at $N_{i}=D^{2} / 4 d_{1} d_{2}$ when $N_{m}=D / 2 d_{2}$, and it equals zero when $N_{m}=D / d_{2}$. We use the parameter values $D=1000, d_{1}=200, d_{2}=100$. A mercenary participating in the attack thus earns $200\left(\frac{N_{i}}{N_{m}}\right)+100 N_{m}$, with a minimum value of $200 N_{i}+100\left(\right.$ when $\left.N_{m}=1\right)$ to $20 N_{i}+$ 1000 (when $N_{m}=10$ ). 
The payoff $200 N_{i}+100$ exceeds 1000 when $N_{i} \geq 5$. Thus, $N_{m}=0$ is not an equilibrium when $N_{i} \geq 5$. Since $N_{i}$ starts at 20 in period 1 and decreases by 2 in each period when the target is not met, period 9 is the first possible period wherein $N_{i} \geq 5$ is not satisfied. Since the payoff to participating is always higher for the lone mercenary in all but the last two periods, all participants participate in the attack until the $9^{\text {th }}$ period, after which none participate (assuming that others likewise will not participate in the final two periods). Hence, a possible equilibrium is that all participants participate in the first eight periods, and none participate in the final two periods. ${ }^{32}$

Participants are aware of the risk that if everyone does not participate, satisfying the requirement in equation (3) may be impossible when $N_{i}$ is small. From equation (3) we can predict that participants are more likely to participate when $N_{i}$ is large than when $N_{i}$ is small. Observe from equation (1) that $\pi_{m}=d_{2} M$ when $N_{i}=0, N_{m}=M \geq 1$, and the mercenary participates in the attack. When $d_{2} M<D$, so that not enough participants participate in the attack to guarantee the outside option payoff $D$ even when $N_{i}=0$, then $N_{m}=M$ is not an equilibrium. That makes it even more risky for participants to hope that all participants participate. Thus Arthur (1994, p. 409) writes for his formulation of the bar problem that "there is not a deductively rational solution.... [I]f all believe few will go, all will go. But this would invalidate that belief. Similarly, if all believe most will go, nobody will go, invalidating that belief. Expectations will be forced to differ."

\section{Implementation}

The computerized experiment was conducted at the University of Texas at Dallas using the z-Tree toolbox for economic experiments developed by Fischbacher (2007). In each

\footnotetext{
${ }^{32}$ However, the participants may adopt a wait-and-see approach, causing them to participate in the last two periods, if the target happens to be met during the first eight periods.
} 
period the participants have 60 seconds to decide whether or not to participate in the terrorist attack. If no entry is made, the default choice of not participating is recorded. At the end of each session the participants were paid their earnings in cash, where 1000 tokens $=\$ 1$. We conducted a total of 23 sessions: seven sessions for the baseline treatment; eight sessions for the leader and communication treatments. Communication was free form, i.e., participants could post anything they desired. In most cases, participants suggested which participants (IDs 1 through 10) should participate in the attack. Participants were told that any messages could be posted, omitting profanity and identifying information. Each session contained two sets of ten periods. The two sets were independent observations in the analysis, and each set was studied separately. Experimental parameters were set at $D=1000, d_{1}=200, d_{2}=100$ for all treatments.

\section{Results}

Fig. 2 shows the frequency of successful coordination for the three treatments. For the baseline treatment, successful coordination occurred a total of seven times for the first ten periods, and eight times over the last ten periods. For the leader treatment successful coordination occurred 11 times for the first ten periods, and 19 times for the last ten periods. For the communication treatment, successful coordination occurred 19 times for the first ten periods, and 24 times for the last ten periods.

\section{Insert Figure 2 about here}

Given the small sample size, it is difficult to calculate the non-parametrics. However, to give us a sense of whether these results are significant, we calculate the proportions of successful coordination over all periods. These are not perfect comparisons since the periods are not independent. That being said, we find that when comparing all periods, coordination in the leader treatment is higher (using a two-tailed test of proportions: $\mathrm{p}<0.10$ ) than in the 
baseline, and coordination in the communication treatment also is higher $(\mathrm{p}<0.01)$.

Furthermore, coordination in the communication treatment is higher than in the leader treatment $(\mathrm{p}<0.10)$. This suggests that severing communications on the ground (between mercenaries) yields greater returns than severing communications between leaders and frontline operatives.

One method to check the robustness of our findings is to bootstrap the data and run regressions using the number of coordination events in the treatments. The bootstrap method is useful when dealing with small samples, which is the case for us, as the unit of analysis is the session. Table 1 shows the regression results comparing the leader and communication treatments to the baseline. Model 1 conducts the analysis for the first ten periods, while model 2 conducts the analysis for the final ten periods. Model 3 pools the periods and clusters by session. For each model, 10,000 bootstrap repetitions were conducted (OLS specification).

\section{Insert Table 1 about here}

As we can see from Table 1, allowing the leader to communicate leads to a modest increase in coordination (by 0.375 successes on average) in the first ten periods, but the difference is not significant. Leaders with experience (in the last ten periods) are significantly more successful, with 1.23 coordination successes relative to the baseline $(p<0.05)$. The communication treatment, by contrast, yields about 1.5 coordination successes for inexperienced participants $(\mathrm{p}<0.01)$, and 1.86 coordination successes for experienced participants $(\mathrm{p}<0.05)$ over the no-communication baseline. This analysis confirms that communication in both forms matters. When allowed to communicate, participants were able to coordinate more frequently than participants that were not allowed to do so. Secondly, this also suggests that one form of communication (peer communication) was more effective than the other (leader communication). 
To explore the second suggestive piece of evidence, we conduct the same analysis on the leader and communication treatments by themselves. Table 2 presents the results of the analysis. Here, the results clearly show that the communication treatment is more effective in facilitating coordination in the first ten periods $(\mathrm{p}<0.01)$. Experience diminishes this gap as leaders become more effective in the last ten periods over time $(\mathrm{p}=0.548)$. Thus, when pooling both periods, the communication treatment is marginally better at facilitating cooperation than the leader treatment $(\mathrm{p}=0.106)$.

\section{Insert Table 2 about here}

Table 3 shows the success of the eight leaders in the leader treatment based on the number of times they obtain successful coordination. The last ten periods are equally successful or more successful than the first ten periods. We can split the data by successful and unsuccessful leaders, where a successful leader is defined as one that had two coordination successes in the first ten periods. Three leaders fit this criterion, while five leaders are deemed unsuccessful. We will discuss this criterion further in the next section.

\section{Insert Table 3 about here}

\section{Discussion}

In the baseline treatment, any coordination activity is rather remarkable. As mentioned, there are clear incentives to participate, little reason to abstain from participation in the first eight periods, and no incentive to participate in the final two periods. However, participants still were able to coordinate successfully once per session, particularly towards the final periods (where coordination was easier because just one person was needed to participate in the attack). Clearly, some subjects were focused on meeting the target and, hence, increasing future payoffs while sacrificing current payoffs.

For the leader treatment, most noteworthy is the substantial learning improvement from the first ten to the last ten periods ( $\mathrm{p}<0.05$ using OLS). In addition, successful 
coordination was 1.75 times greater than in the baseline treatment. This is mainly due to different leader strategies, since they had strong incentives to facilitate coordination. The quality of communications varied considerably. Some leaders encouraged the participants to think of the group and gave praise when the target was met. Others blamed the participants when the target was not met, and some gave up when the target repeatedly was not met. Several leaders chose simply to specify which participants should participate in each period, not explaining why and not providing praise or blame.

The data show that five requirements are necessary for leaders to facilitate coordination. First, their messages should to be clear and unequivocal, specifying exactly which participants should participate and which should not. Second, the messages should be supportive, encouraging, and emphasize group over self. Third, the leaders' messages should contain an explanation for their recommendations, so that the participants detect the presence of a plan over future periods. Fourth, the messages should be unbiased and allow all participants to participate. Fifth, initial success in the first few periods is crucial for building trust. For the three successful leaders (as defined by organizing two successful attacks in the first ten periods), the key ingredients for success were clear instructions and fair treatment. The least successful of those three did not forecast their strategy, nor engage in supportive communication. The second most successful leader was supportive in his/her communications, but did not engage in forecasting. Finally, the most successful leader had all four of these ingredients, and that session had the highest number of coordination events across all three treatments. Additionally, learning was most pronounced in this treatment as well, with a majority of unsuccessful leaders also showing improvement.

For the peer communication treatment, learning improvement was more moderate from the first ten to the last ten periods ( $\mathrm{p}=0.605$ using OLS). However, peer communication did have an impact on coordination: it was 2.51 times larger than for the baseline treatment. 
Two basic themes in the discussions among peers are (1) to agree on who shall participate in a particular period, and (2) how to proceed in the subsequent period depending on whether or not the participation target was met. The participants were quite conscious of group loyalty, in the sense of following up on what they agreed, versus unilateral defection (which usually meant participating without agreeing to participate).

\section{Conclusion}

In this paper, we test the effect of severing communication between (1) terrorist group leaders and front-line terrorists, and (2) front-line terrorists themselves. We test the salience of these two counter-terrorism policies by constructing a game focusing on the behavior of a particular type of terrorist agent: the mercenary. We exploit the "bar problem" (Arthur 1994) because it captures the essential elements of the coordination problem faced by terrorist groups. In our model, successful terrorist attacks are the outcomes of coordination problems, requiring an optimal mix of two types of participating agents, ideologues and mercenaries. The counter-terrorism policies hinder communication, either between coordinating participants, or between a leader and coordinating participants. Successful attacks draw ideologues into a terrorist organization, while unsuccessful attacks push ideologues away. This increase (decrease) in ideologues is reflected in the growth, decay, and transformation of terrorist groups.

By severing communication links, we observe the effects of these counter-terrorism policies on coordination, and hence on the decline of terrorist groups. The policies focus on disrupting communication between the core and the cell, and within the cell itself. Since very little is known about the effectiveness of each strategy in contributing to terrorist group growth (decay) through direct observation, we use a laboratory experiment to test the relative efficiency of these policies. We find that disrupting communication within terrorist cells is far more effective in reducing terrorist attacks than preventing group leaders from 
communicating with their followers. On average, doing the former reduced the frequency of coordination from $26.88 \%$ to $10.71 \%$. When we contrast this with severing communication between the core and the terrorist cell (which had a success rate of $18.75 \%$ ), we find evidence for disrupting communication within terrorist cells to be an effective strategy. That being said, we also note that coordination was also high in the leader treatment (40\% with the most successful leader), indicating that a strong leader can also be an effective facilitator. Therefore, counterterrorism policies disrupting communication between the core and the cell should not be ignored. Future research in this area will focus on the incentives for mercenaries, including outside options, increasing probability of detection, whistleblowing, and social networks, while also modeling ideologues and captive participants. If the challenge of identifying terrorists can be overcome, one implication for policy making is that disrupting communications among frontline fighters is effective, and may be even more effective than focusing on group leaders. Our results have implications for scholars interested in developing behavioral theories for terrorist agents as well as for policymakers interested in gauging the effectiveness of counterterrorist policies. While it is widely noted that many terrorist group abandon their political goals and turn toward criminal activities, little effort has been devoted to constructing a theoretical perspective for studying such transformations. Efforts at understanding the behavioral motivations behind participating in violent dissident activities may open new areas of research in counterterrorism policies.

Acknowledgements: We thank the National Science Foundation for financial support and participants at the conference "Bridging areas of expertise: funding research on terrorism," October 7-10, 2010, http://cbees.utdallas.edu/tsconference/home.php for useful comments. We acknowledge support by NSF award BCS-0905044. We thank three referees of this journal and the editor for useful comments. 


\section{References}

Abu-Amr, Z. (1993). Hamas: a historical and political background. Journal of Palestine Studies, 22(4), 5-19.

Ahmed, H. (2005). Palestinian resistance and 'suicide bombing': causes and consequences. In Toro Bjorgo (ed) Root causes of terrorism: myths, reality and ways forward. London: Routledge: 87-102.

Andreoni, J. (1989). Giving with impure altruism. Journal of Political Economy, 97, 14471458.

Andreoni, J. (1990). Impure altruism and donations to public goods: a theory of warm-glow giving. Economic Journal, 100, 446-477.

Arthur, W.B. (1994). Inductive reasoning and bounded rationality. American Economic Review (Papers and Proceedings), 84, 406-411.

Atran, S. (2002). In gods we trust: the evolutionary landscape of religion. Oxford: Oxford University Press.

Berman, E. \& Laitin, D. (2005). Hard targets: theory and evidence on suicide attacks. NBER Working Paper No. 11740. November.

Betancourt, I. (2011). Even silence has an end: my six years of captivity in the Colombian jungle. New York: Penguin.

Blomberg, B., Engel, R. \& Sawyer, R. (2011). On the duration and sustainability of transnational terrorist organizations. Journal of Conflict Resolution, 54(2), 303-330.

Bloom, M. (2005). Dying to kill: the allure of suicide terror. New York: Columbia University Press.

Bowles, S. \& Gintis, H. (2011). Cooperative species: human reciprocity and its evolution. Princeton, N.J.: Princeton University Press.

Carter, D.B. (2012). A blessing or a curse? State support for terrorist groups. International Organization, 66(1), 129-151.

Crenshaw, M. (1991). How terrorism declines. Terrorism and Political Violence, 3(1), 69-87.

Cronin, A.K. (2006). How al-Qaida ends: the decline and demise of terrorist groups. International Security, 31(1), 7-48.

Cronin, A.K. (2009). End of terrorism: understanding the decline and demise of terrorist campaigns. Princeton: Princeton University Press.

Dishman, C. (2006). The leaderless nexus: when crime and terror converge. In R. D. Howard \& R. L. Sawyer (eds.) Terrorism and Counterterrorism. Dubuque, IA.: McGraw Hill, 36782.

English, R. (2004). Armed struggle: the history of the IRA. Oxford: Oxford University Press.

Faria, J. \& Arce, D. (2012). A vintage model of terrorist organizations. Journal of Conflict Resolution, 56(4), 629-650.

Fischbacher, U. (2007). z-tree: zurich toolbox for ready-made economic experiments. Experimental Economics, 10(2), 171-178.

Gaibulloev, K. \& Sandler, T. (2013). Determinants of the demise of terrorist organizations. Southern Economic Journal, 79(4), 774-792. 
Gaibulloev, K. \& Sandler, T. (2014). An empirical analysis of alternative ways that terrorist groups end. Public Choice, 160(1-2), 25-44.

Gupta, D. K. (1990). The economics of political violence: the effects of political instability on economic growth. New York: Praeger.

Gupta, D.K. (2008). Understanding terrorism: the life cycle of birth, growth, transformation, and demise. New York: Routledge.

Gupta, D. K. \& Mundra, K. (2005). Suicide Bombing as a Rational Strategy: Hamas and the Islamic Jihad. Terrorism and Political Violence, 17(4), 573-598.

Gupta, D.K., Horgan, J. \& Schmid, A.P. (2009). Terrorism and Organized Crime: A Theoretical Perspective. In D. Canter (ed.) The Faces of Terrorism: Multidisciplinary Perspectives. London: Wiley-Blackwell, 2009, pp. 123-136.

Hausken, K. (1996). Self-interest and sympathy in economic behavior. International Journal of Social Economics, 23(7), 4-24.

Heskin, K. (1985). Social disintegration in Northern Ireland - a five-year update. Economic and Social Review, 16(3), 187-199.

Hoffman, B. (1998). Inside terrorism. New York: Columbia University Press.

Holland, J. \& McDonald, H. (1984). INLA: deadly division. Dublin: Torc.

Maloney, Ed (2002). The secret history of the IRA. New York: W. W. Norton.

Mannes, A., Sliva, A., Subrahmanian, V.S. \& Wilkenfeld, J. (2008). Stochastic opponent modeling agents: a case study with hamas. Proceedings of the second international conference on computational cultural dynamics (ICCCD-07), 49-54, Edited by V.S. Subrahmanian \& Arie Kruglanski, College Park, Maryland, 15-16 September 2008. Published by The AAAI Press, Menlo Park, California, http://www.aaai.org/Library/ICCCD/icccd08contents.php.

Mishal, S. \& Sela, A. (2000). Palestinian Hamas: vision, violence, and coexistence. New York: Columbia University Press.

Mukherjee, K. \& Yadav, R.S. (1980). Bhojpur: naxalism in the plains of bihar. Delhi. Radha Krishna Prakashan.

Olson, M. (1965). The logic of collective action: public goods and the theory of groups. Cambridge, Mass.: Harvard University Press.

Palmer, D.S. (1995). The revolutionary terrorism of Peru's shining path. In M. Crenshaw (ed.) Terrorism in Context. University Park, PA: Pennsylvania State University Press.

Pape, R.A. (2003). The strategic logic of suicide terrorism. American Political Science Review, 97, 343-361.

Phillips, P. (2011). The life cycle of terrorist organizations. International Advances in Economic Research, 17(4), 369-385.

Rapoport, D.C. (1992). Terrorism. In M. E. Hawkesworth \& M. Kogan (eds.) Routledge Encyclopedia Government and Politics, Vol 2. London: Routledge.

Rivers, C. (2014). Al-Qaeda: the history of the world's most notorious terrorist organization. Charles Rivers Editors.

Rogers, S. (2003). Beyond Abu Sayyaf. Foreign Affairs, 83(1), 5-21. 
Rose-Ackerman, S. (1996). Altruism, non-profits and economic theory. Journal of Economic Literature, 36, 701-728.

Sandler, T. (2014). The analytical study of terrorism: taking stock. Journal of Peace Research, 51(2), 257-271.

Schmid, A.P. \& de Graaf, J. (1982). Violence as communication: insurgent terrorism and western news media. Beverly Hills, CA.: Sage.

Shapiro, J.N. (2013). The terrorist's dilemma: managing violent covert organizations. New Jersey: Princeton University Press.

Shapiro, J.N. \& Siegel, D.A. (2007). Underfunding in terrorist organizations. International Studies Quarterly, 51(2), 405-429.

Shapiro, J.N. \& Siegel, D.A. (2012). Moral hazard, discipline, and the management of terrorist organizations. World Politics, 64, 39-78

Singh, P. (2006). The Naxalite movement in India. New Delhi: Rupa \& Co.

Tullock, G. (1974). The social dilemma: the economics of war and revolution. Blacksburg, VA: Center for Study of Public Choice.

Wright, L. (2007). The looming tower: Al-Qaeda and the road to 9/11. New York: Vintage. 
Table 1. Coordination success in treatments

\begin{tabular}{|llll|}
\hline $\begin{array}{l}\text { Dependent variable: number of successful coordination } \\
\text { events }\end{array}$ & \multicolumn{3}{l|}{} \\
\hline Periods & First ten & Last ten & Pooled \\
& I & II & III \\
\hline Leader treatment & 0.375 & $1.232 * *$ & $0.804 * *$ \\
& $(0.28)$ & $(0.93)$ & $(0.40)$ \\
\hline Communication & & & \\
treatment & $1.500 * * *$ & $1.857 * *$ & $1.679 * * *$ \\
& $(0.38)$ & $(0.93)$ & $(0.48)$ \\
\hline Constant & $1.000 * * *$ & $1.143 * * *$ & $1.071 * * *$ \\
& $(0.21)$ & $(0.26)$ & $(0.20)$ \\
\hline R-squared & 0.486 & 0.165 & 0.206 \\
Wald & 15.320 & 7.070 & 14.000 \\
P-Value & 0.001 & 0.029 & 0.001 \\
Replications & 9993 & 9998 & 9997 \\
Observations & 23 & 23 & 46 \\
\hline
\end{tabular}

Note: $* \mathrm{p}<0.1, * * \mathrm{p}<0.05, * * * \mathrm{p}<0.01$. OLS estimates, bootstrapped standard errors in parentheses. The dependent variable is the number of successful coordination events in all periods. Model 1 provides estimates for treatment differences (compared to the baseline) for the first ten periods, while model 2 provides estimates for the final ten periods. Model 3 pools the periods and clusters by session to account for any across-period correlations.

Table 2. Coordination success in leader and communication treatments

\begin{tabular}{|llll|}
\hline $\begin{array}{l}\text { Dependent variable: number of successful coordination } \\
\text { events }\end{array}$ & \multicolumn{3}{l|}{} \\
\hline Periods & First ten & $\begin{array}{l}\text { Last ten } \\
\text { I }\end{array}$ & $\begin{array}{l}\text { Pooled } \\
\text { III }\end{array}$ \\
\hline $\begin{array}{l}\text { Communication } \\
\text { treatment }\end{array}$ & $1.125^{* * *}$ & 0.625 & 0.875 \\
& $(0.36)$ & $(1.04)$ & $(0.54)$ \\
\hline Constant & $1.375^{* * *}$ & $2.375^{* * *}$ & $1.875^{* * *}$ \\
& $(0.18)$ & $(0.55)$ & $(0.34)$ \\
\hline R-squared & 0.391 & 0.024 & 0.074 \\
Wald & 9.520 & 0.360 & 2.600 \\
P-Value & 0.002 & 0.548 & 0.107 \\
Replications & 10000 & 9999 & 10000 \\
Observations & 16 & 16 & 32 \\
\hline
\end{tabular}

Note: $* \mathrm{p}<0.1, * * \mathrm{p}<0.05, * * * \mathrm{p}<0.01$. OLS estimates, bootstrapped standard errors in parentheses. The dependent variable is the number of successful coordination's in all periods. Model 1 provides estimates for treatment differences (compared to leader) for the first ten periods, while model 2 provides estimates for the final ten periods. Model 3 pools the periods and clusters by session to account for any across period correlations. 
Table 3. Coordination success for the eight leaders in the leader treatment (sessions 2,4,7,11-14,17), and scores for five requirements.

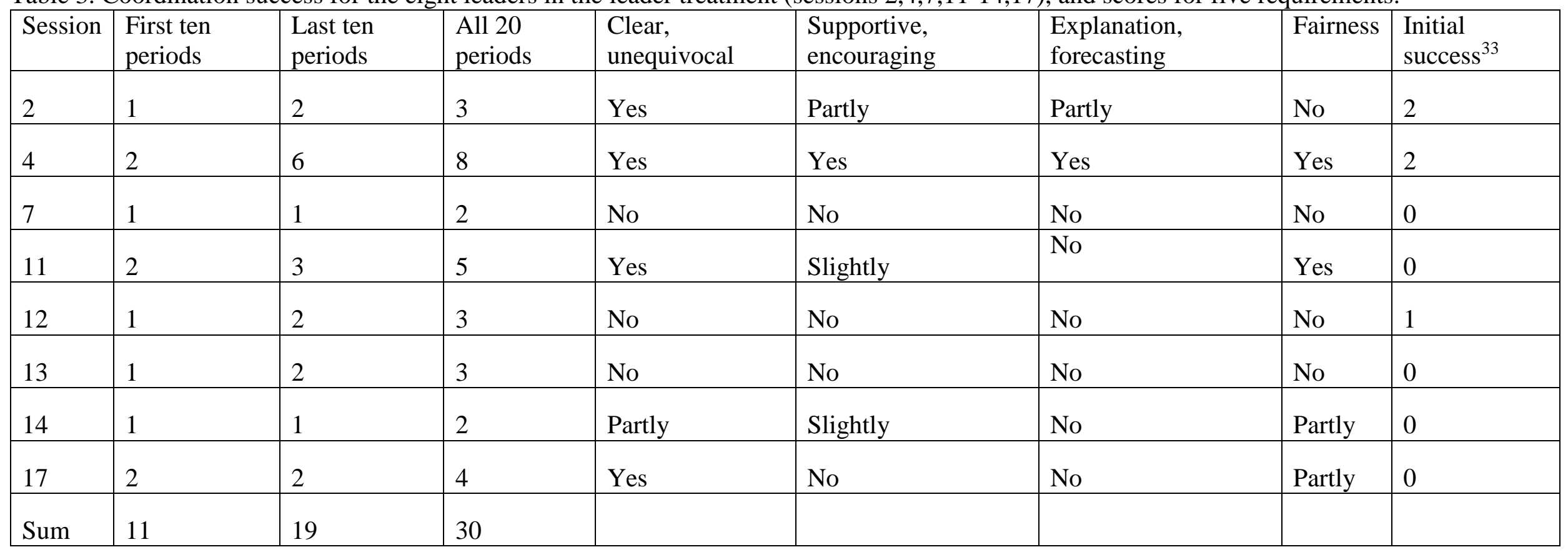

\footnotetext{
${ }^{33}$ Initial success scores the number of successful coordination events in periods $1,2,11,12$, which is a number between 0 and 4
} 

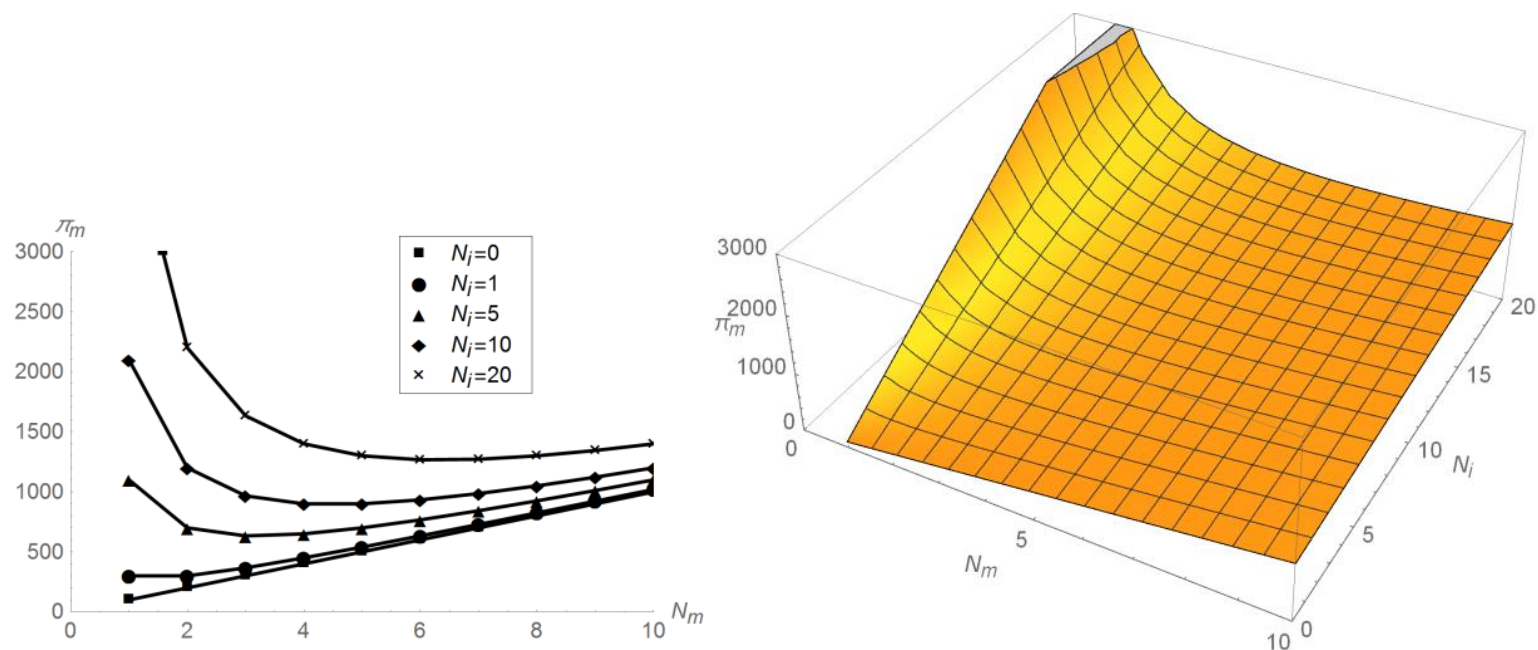

Fig. 1. Each mercenary's payoff, $\pi_{m}$, as a function of the number $N_{m}$ of mercenaries and the number $\mathrm{N}_{\mathrm{i}}$ of ideologues, $d_{1}=200, d_{2}=100, M=10$.

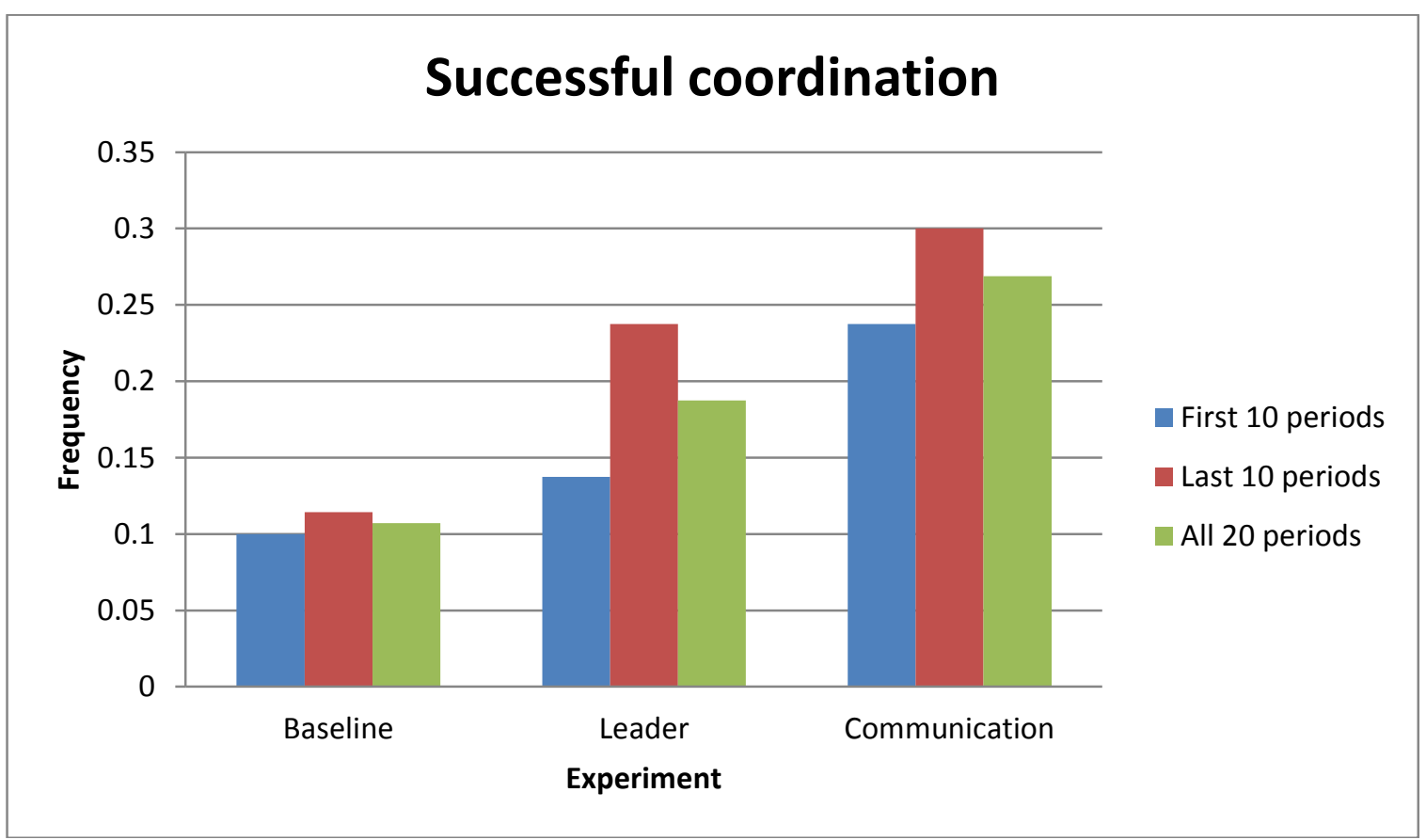

Fig. 2. Frequency of successful coordination for the three treatments. 